\title{
Aerobics Exercises Effect on Weight Loss for Students with Overmuch Obesity in Kuwait
}

Dr/ Muhammad Ali Hussein Al-Khalifa*

Introduction and Research Problem

Obesity is considered one of the most current important problems which spreads among children as a phenomena in the last two decades of the Twentieth century. This phenomena is deserved to be studied because of the related diseases accompanied it. It becomes a necessity to study it starting from the precise definition of the used idioms at this area, like; weight gain, fatness, obesity and body elements change (IYA|: I $)$

Jassem Ramadan Ali (2010) highlighted that the fast economic growth in urban societies including Kuwaiti society led to prosperity then enormous social changes which resulted in obesity and in the numbers of those who suffer from related diseases which hit the international rates as more than 100,000 Kuwaiti citizens suffer from obesity and its psychological and health effects. (1 (T: :

Nowadays sports are practiced for two main purposes, health and prevention of lack of movement diseases on top of it is obesity. $(0: 0)$

Fonseca's and others study (Fonseca et al., 2013) showed that using aerobics with power exercises are the main pillars for the sports based over much obesity therapy, it recommended also the using of individual training programs for those who suffer from overmuch obesity (13)

Kolterman (2011) and Roudsepp (2002) indicated that the physical activities included in diet and weight keeping programs depend on the physical load used, its duration and the number of the training units. (I YVO: I $\Sigma$ ) ( $V 0: 17$ )

Nyads. D \& Hogan define aerobics exercises as heart and muscles non-stressful exercises which needs longer time to perform, more effective, trains heart muscle on pumping more blood and trains respiratory system on consuming oxygen. $(\Gamma \leq: 10)$

Abou El-Ela Abdulfattah mentioned that the main duty of performing aerobics lies on 
respiratory system where it needs longer time to perform, is more effective, it trains heart muscle on pumping more blood and trains respiratory system on consuming oxygen. $(r \leq: r)$

Ibrahim Saleh (2009) copying from Khaled Heekal (2000) pointed that aerobics benefits could be summarized in the increasing of metabolism rate where some studies showed that this exercises could increase body metabolism rate, this high rate allows burning calories with increasing rates during rest times.

In addition adding aerobics to the daily training programs leads to burning extra calories during training so the metabolism activity continues within the normal rates $(\wedge \leq: !)$

The researcher noticed that there is an awareness problem related to healthy habits, Dietary behavior and the lack of practice which leads to increase in metabolism related diseases, so he recommends to solve the problem from the roots, to begin with the school age to create a generation with health and sportive awareness and the right Dietary behavior. At this point comes the role of ministry of education in taking steps to invest in physical education sessions to apply sports programs and exercises in order to prevent metabolism in the early stages for the school ages.

\section{Research Purpose}

The research aims to investigate the effect of using aerobics on weight loss for the morbid obesity medium stage Kuwaiti students.

\section{Research Assumptions:}

1- There are differences with statistical indications between the means of the pre and after measurements for the body components variables (body heaviness $\mathrm{BH}-$ body mass indicator BMI- body fats BF- fats weight FW- body mass without fats LBM) in favor of the after measurements for the experimental group ?

2- There are differences with statistical indications between the means of the pre and after measurements for the body components variables (body heaviness $\mathrm{BH}$ - body mass indicator BMI- body fats BF- fats weight FW- body mass without fats LBM) in favor of the after 
measurements for the control group?

3- There are differences with statistical indications between the means of the after measurements for the body components variables in both the experimental and control groups ( body heaviness $\mathrm{BH}-$ body mass indicator BMIbody fats BF- fats weight FWbody mass without fats LBM) in favor of the after measurements for the experimental group sample?

Research Terminologies Overmuch Obesity

The degree of obesity when the BMI reaches or exceeds $30 \mathrm{kgm} / \mathrm{m}^{2}$ which leads to difficulties in practicing daily natural physical activities, physiological functions or may cause the appearance of some diseases ( $171: 1 \mathrm{~V})$

Body Mass Index

An indicator describes the physical structure and calculated by dividing body weight in kgms on height squared in $\mathrm{m}^{2}$ ( rol:r)

\section{Aerobic Exercises}

That type of exercises which use the body's big muscle groups through repeated and continuous harmonic moves which makes the respiratory system provide the muscles with the needed oxygen $(\vee: 11)$

\section{Earlier Researches:}

- Hussein Ali Al-Dawoody's study (2015) (7) " the effect of aerobics diet program on physical and physiological variables for morbid obesity women using computer ", the study aimed to design aerobic and physical program using computer for diet and to study its effect on physical and physiological variables, the experimental methodology was used with one group design (pre and after) and the sample was chosen by the propulsive way from morbid obesity women, 30 Libyan women from Musrata were chosen, the research showed an effect for the program on diet and physical and physiological variables, it recommended applying this programs for its positive effect on diet.

- Amal Muhammad Mefrg's study (2007) (4) with the title “ the effect of a proposed rhythmic aerobic arts program and used themes on weight loss, fats thickness and stress for ladies ( 30 to 45 years ). The study aimed to identify the effect of a proposed rhythmic aerobic arts program and used themes on weight loss, fats 
thickness and stress for ladies ( 30 to 45 years ), the sample of the study was 20 Bahraini ladies, the study showed that the program led to weight loss and lessen the fat thickness and the absolute fat weight in addition to its positive effect on decreasing psychological stress partially.

- Fathy Muhammad Nada's study (2006)(9) aimed to identify the effect of using aerobics physical activity on body building and physical performance for morbid obesity 7 years children, the study sample was propulsive consisted of 33 morbid obesity student and was divided into three groups, the experimental methodology was used, a significant differences were noticed in body fats decrease and motor performance increase.

\section{Research Procedures \\ Research Methodology:}

The researcher used the experimental methodology on to groups, one of them is experimental and the other is a control group which suited the research better.

\section{Population and Research Sample}

The research population was morbid obesity middle grade Kuwaiti students who were selected through exploratory study done by the researcher, 30 students were selected according to BMI, 6 of them were selected for the pilot study to legalize the research experiment, 2 were excluded for emergent medical situation, then the propulsive sample was on 24 middle grade students, the table below shows population distribution and research sample.

Table (1)

Research sample distribution

\begin{tabular}{|c|c|c|c|c|c|c|}
\hline \multirow{2}{*}{$\begin{array}{c}\text { Research } \\
\text { population }\end{array}$} & \multirow{2}{*}{$\begin{array}{c}\text { Pilot } \\
\text { sample }\end{array}$} & \multirow{2}{*}{$\begin{array}{c}\text { Main } \\
\text { sample }\end{array}$} & \multirow{2}{*}{ percentage } & \multicolumn{2}{|c|}{ Main sample } & \multirow[b]{2}{*}{ excluded } \\
\hline & & & & Experimental & Control & \\
\hline 30 & 6 & 22 & $73.3 \%$ & 10 & 10 & 2 \\
\hline \multicolumn{7}{|c|}{$\begin{array}{l}\text { Sample Choosing Conditions: } \\
\text { To have morbid obesity } \\
\text { (> or }=40 \mathrm{~kg} / \mathrm{m} 2) \\
\text { the The constancy on } \\
\text { acceptance of being part of the } \\
\text { experiment }\end{array}$} \\
\hline
\end{tabular}


sample for the height, weight, age and BMI variables as described in the following table.

Table (2)

Mathematical mean, standard deviation and skewness factor for the height, weight, age and BMI variables for the collective research sample $(n=20)$

\begin{tabular}{|c|c|c|c|c|}
\hline $\begin{array}{l}\text { Research } \\
\text { variables }\end{array}$ & unit & $\begin{array}{l}\text { standard } \\
\text { deviation }\end{array}$ & $\begin{array}{c}\text { Mathematical } \\
\text { mean }\end{array}$ & $\begin{array}{c}\text { skewness } \\
\text { factor }\end{array}$ \\
\hline Age & Yea & $1 . V$ & 17.8 & $-\cdot .77 \pi$ \\
\hline Height & Centimeters & $\varepsilon . V$ & $17 V . r$ & $-\cdot . r T$ \\
\hline Weight & Kilograms & 1.0 & 1.0 .0 & $\because .91$ \\
\hline BMI & $\mathrm{Kgm} / \mathrm{m}^{2}$ & $r .+1$ & $\sum 1.1$ & • YTY \\
\hline
\end{tabular}

Table 2 shows that skewness factors for research sample individuals was between $(3,-3)$ in the variables of height, weight, age and BMI which says that the research sample is homogeneous.
Equivalence of control and experimental research groups:

The researcher made the control and experimental research groups in the physical variables equivalent as shown in table 3.

Table (3)

Mathematical mean, standard diversion and $T$ value for body components variables and the numeric level of the collective research sample $(\mathrm{n} 1=\mathrm{n} 2=10)$

\begin{tabular}{|c|c|c|c|c|c|c|c|}
\hline \multirow[t]{2}{*}{ Variables } & \multirow[t]{2}{*}{ units } & \multicolumn{2}{|c|}{$\begin{array}{l}\text { Control } \\
\text { groupN=10 }\end{array}$} & \multicolumn{2}{|c|}{$\begin{array}{l}\text { Experimental } \\
\text { group } \mathrm{N}=10\end{array}$} & \multirow{2}{*}{$\begin{array}{l}\mathbf{T} \\
\text { value }\end{array}$} & \multirow[t]{2}{*}{ Significance } \\
\hline & & MM & SD & MM & SD & & \\
\hline Body height & $\overline{\mathrm{Cm}}$ & $171 . \cdot V$ & 1.71 & ITV.rT & $7 . \Gamma \wedge$ & 0.837 & No \\
\hline $\mathrm{BH}$ & Kgm & 110.90 & 0.11 & $11 \Gamma . \wedge \Lambda$ & 8.70 & I.rYs & No \\
\hline BMI & $\mathrm{Kgm} / \mathrm{m}^{2}$ & $\varepsilon Y . r$ & $0 . r \mu$ & $\varepsilon 1 . V V$ & 7.10 & .011 & No \\
\hline $\mathrm{BF}$ & $\%$ & r. & r.or & rr.vo & $r . \vee \varepsilon$ & $-1 . r \cdot 0$ & No \\
\hline FW & Kgm & 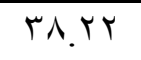 & T.V & rq.r & r.r. & $\cdot V \cdot \varepsilon_{-}$ & $\mathrm{No}$ \\
\hline LBM & kgm & $\Lambda r .00$ & $\varepsilon . \wedge \mathrm{V}$ & 11.97 & $7 . V \leqslant$ & $1.7 \leqslant 1$ & No \\
\hline
\end{tabular}

(T) value at 0.05 level $=2.262$ 
Table 3 shows absence of statistical significant differences between the two research groups in body components variables which says that the research samples are equivalent.

\section{Data collecting tools:}

- Restameter for measuring height in $\mathrm{Cm}$.

- $\quad$ Medical weight scale

- $\quad$ Body State Analyzer for measuring body components (fats weight, body weight without fats, body water percentage)

\section{Pilot Study:}

The researcher made a pilot study in Tuesday 23/9/2015 and Wednesday 24/9/2015 on 4 students sample of research population and not from the original research factor with those aims:

- Assure the efficiency and competency of the tools

- Define the difficulties which may face the researcher when measuring

- Estimate the needed time for the tests

And the results were:

- The tools are function and ready to use

- $\quad$ The system is valid and he shall continue the training program
- $\quad$ The qualitative exercises are reasonable and the identification of each training timing, repeats and rests for research sample.

Aerobics training program content time line:

The training programs duration varies from 6 to 12 weeks and number of training units aren't less than 3 units weekly, this period is enough to see the physical effect. ) $(\vee Y: \wedge)(r \cdot \wedge:)$.

So the researcher sees that 8 weeks duration is enough to have 24 training units, the time of aerobics varies from 35 to 40 minutes and applied on the experimental group only, the time of the training unit is 60 minutes including warm-up, the main part, and the final part.

\section{Research execution process:}

The researcher has made his pre measurements for body components variables $(\mathrm{BH}-$ $\mathrm{BMI}$ - BF - FW- LBM) for both of control and experimental group at 30/9/2015.

\section{Applying training program:}

Qualitative exercises have been applied on the experimental group for 8 weeks, 3 training units a week on Saturday, 
Monday and Wednesday with total units equals 24 unit at the period from 3/10/2015 to $28 / 11 / 2015$ at the sports club.

\section{Post measurements:}

The researcher has made his post measurements for body components variables $(\mathrm{BH}-$ BMI - BF - FW- LBM) for both of control and experimental group at 29/11/2015 following the same pre measurements procedures.

Statistical processes: mathematical mean - standard deviation $-\mathrm{T}$ value percentage

\section{Results and Discussion:}

Table (4)

The significance of differences between pre and post measurements for the experimental group in body components variables $(\mathrm{N}=10)$

\begin{tabular}{|c|c|c|c|c|c|c|c|c|}
\hline \multirow{2}{*}{ Variables } & \multirow{2}{*}{ units } & \multicolumn{2}{|c|}{$\begin{array}{c}\text { Pre } \\
\text { measurements }\end{array}$} & \multicolumn{2}{|c|}{$\begin{array}{c}\text { Post } \\
\text { measurements }\end{array}$} & \multirow{2}{*}{$\begin{array}{c}\mathbf{T} \\
\text { value }\end{array}$} & \multirow{2}{*}{$\begin{array}{c}\text { The } \\
\text { difference } \\
\text { between } \\
\text { means }\end{array}$} & \multirow{2}{*}{$\begin{array}{c}\text { Improvemen } \\
\text { percentage }\end{array}$} \\
\hline & & MM & SD & MM & SD & & & \\
\hline$\overline{\mathrm{BH}}$ & kgm & $11 \pi . \wedge \Lambda$ & 8.70 & 97.00 & $0 . V V$ & *Y.TOY & IV.YT & $\% 10.1 Y$ \\
\hline BMI & $\mathrm{Kgm} / \mathrm{m}^{2}$ & $\varepsilon 1 . V V$ & 7.50 & Tr.70 & 7.0 & $* 0 . r 01$ & 9.11 & $\%$ \% . . \\
\hline $\mathrm{BF}$ & $\%$ & r.Y.Vo & $r . v \leq$ & $r) . r q$ & $\leqslant .70$ & $* 0 . \wedge \leqslant 7$ & $11 . \leqslant 7$ & $\% r \leq .99$ \\
\hline FW & Kgm & rq.rq & $r . r I$ & YT.70 & $\varepsilon V V$ & $* V . r q \leq$ & 10.10 & $\%$ \%9.91 \\
\hline LBM & kgm & 11.97 & $7 . V \varepsilon$ & 19.7 & 0.01 & $* Y .0 \wedge \varepsilon$ & T.T & $\%$ \% .AV \\
\hline
\end{tabular}

T table value at $0.05=2.262$

Table 4 results shows that statistically significant differences appear at (0.05) level between the pre and post measurements for the

experimental group in the variables under research, improvement percentage varied between $(\%$ r.Av، \% \% १.१)

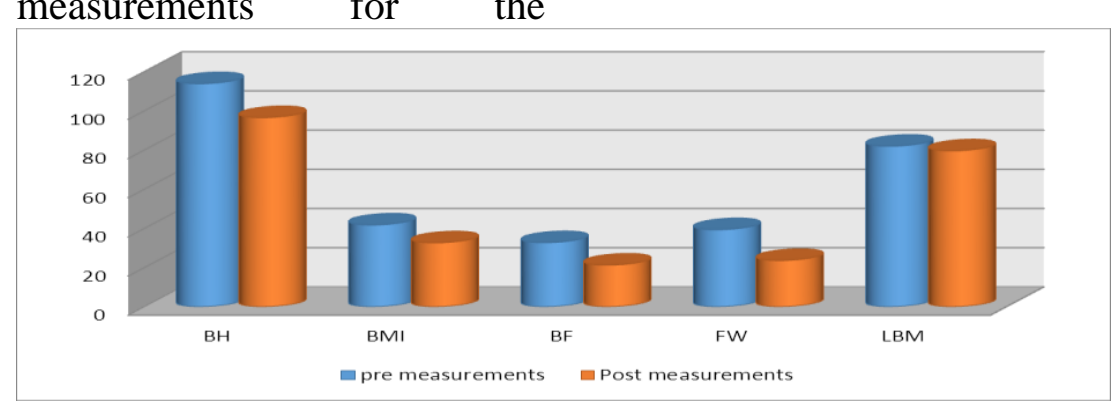

Chart (1) 
Table (5)

The significance of differences between pre and post easurements for the control group in body components variables $(\mathrm{N}=10)$

\begin{tabular}{|c|c|c|c|c|c|c|c|c|}
\hline \multirow{2}{*}{ Variables } & \multirow{2}{*}{ units } & \multicolumn{2}{|c|}{$\begin{array}{l}\text { Pre } \\
\text { measurements }\end{array}$} & \multicolumn{2}{|c|}{$\begin{array}{l}\text { Post } \\
\text { measurements }\end{array}$} & \multirow{2}{*}{$\begin{array}{l}\mathbf{T} \\
\text { value }\end{array}$} & \multirow{2}{*}{$\begin{array}{l}\text { The } \\
\text { difference } \\
\text { between } \\
\text { means }\end{array}$} & \multirow{2}{*}{$\begin{array}{l}\text { Improvement } \\
\text { percentage }\end{array}$} \\
\hline & & MM & SD & MM & SD & & & \\
\hline $\mathrm{BH}$ & kgm & 110.90 & 0.14 & $11 r . \leqslant 0$ & V..0 & $\because 1 \leqslant V$ & T.0 & $\%$ \%.10 \\
\hline BMI & $\mathrm{Kgm} / \mathrm{m}^{2}$ & $\varepsilon r . r$ & Tr & $\leqslant 1 . \leqslant \wedge$ & T. $\leqslant V$ & תrו. &.$A r$ & $\% 1.94$ \\
\hline $\mathrm{BF}$ & $\%$ & $r .1 r$ & r.or & $r \cdot .01$ & $\leq . \wedge 1$ & $. V 1 \leq$ & $.7 r$ & $\% 1.99$ \\
\hline FW & Kgm & TA.YY & $r . V \varepsilon$ & r..0Y & 0.10 & $\therefore \leqslant \vee 0$ & $1 . V$ & $\%$ \% $\varepsilon \varepsilon$ \\
\hline LBM & kgm & $1 r .00$ & $\sum . \wedge V$ & Ar. II & 7.10 & $\because Y V \varepsilon$ & $1 . \varepsilon \varepsilon$ & $\%$ \%.VY \\
\hline
\end{tabular}

(T) value at $0.05=2.262$

Table 5 results doesn't show any statistically significant differences at 0.05 level between the pre and post measurements for the control

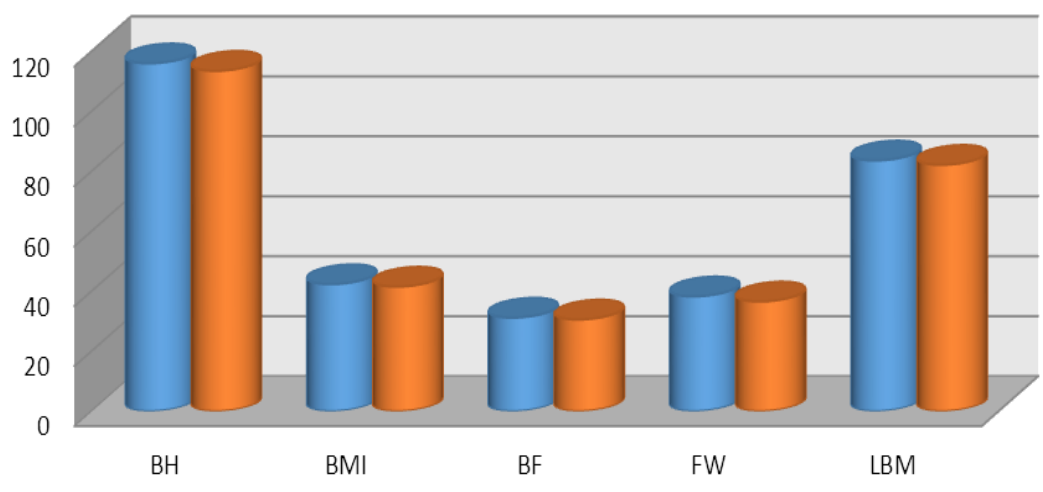

$\square$ Pre measurements $\square$ Post measurements

Chart (2) 
Table (6)

The differences significance between post measurements results for both of research groups in body components variables $(n=10)$

\begin{tabular}{|c|c|c|c|c|c|c|c|c|}
\hline \multirow{2}{*}{ Variables } & \multirow{2}{*}{ units } & \multicolumn{2}{|l|}{$\begin{array}{l}\text { Control } \\
\mathbf{N}=10\end{array}$} & \multicolumn{2}{|c|}{$\begin{array}{l}\text { Experimental } \\
\mathbf{N}=\mathbf{1 0}\end{array}$} & \multirow{2}{*}{$\begin{array}{l}\text { T } \\
\text { value }\end{array}$} & \multirow{2}{*}{$\begin{array}{l}\text { The } \\
\text { difference } \\
\text { between } \\
\text { means }\end{array}$} & \multirow{2}{*}{$\begin{array}{l}\text { Improvement } \\
\text { percentage }\end{array}$} \\
\hline & & MM & SD & MM & SD & & & \\
\hline $\mathrm{BH}$ & kgm & $111 . \leqslant 0$ & $\mathrm{~V} .0$ & 97.00 & $0 . V V$ & $* 7 . r 10$ & 17.9 & $\% \backslash \leq . \wedge 9$ \\
\hline BMI & $\mathrm{Kgm} / \mathrm{m}^{2}$ & $\sum 1 . \leqslant \wedge$ & $7 . \leqslant V$ & Tr.70 & 7.0 & *E.r. & $\Lambda . \wedge r$ & $\%$ \% I \\
\hline $\mathrm{BF}$ & $\%$ & $r \cdot .01$ & $\varepsilon . \wedge 1$ & Y1. 19 & $\varepsilon .70$ & $* \varepsilon .70 Y$ & q.KY & $\% r \cdot . r 1$ \\
\hline FW & $\mathrm{Kgm}$ & r..0Y & 0.10 & rT.70 & $\varepsilon . V V$ & $* r . \vee 01$ & Ir.AV & $\%$ TO.Yร \\
\hline LBM & $\mathrm{kgm}$ & Ar.II & 7.10 & 19.7 & 0.01 & $* r . \wedge q r$ & r.01 & $\%$ \%..0 \\
\hline
\end{tabular}

\section{(T) value at $0.05=2.262$}

Table 6 results shows that statistically significant differences appear at 0.05 level between the pre measurements for the experimental and control groups in the variables under research, improvement percentage varied between $\%$ r. . ० \% ro.r $\varepsilon$

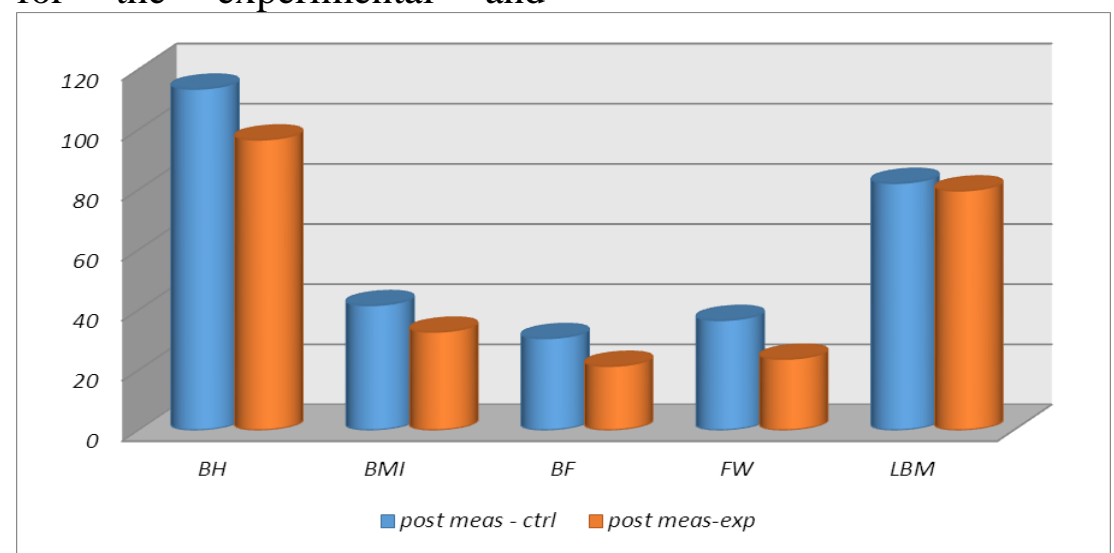

\section{Chart (3)}

\section{Results discussion}

First assumption results discussion

The first assumption stats that there are statistically significant differences between pre and post measurements means for the body components variables (BH - BMI - BF - FW -

LBM) in favor of the post measurements for the experimental group?

Through displaying the results of table 4 and chart 1 we can notice that there are statistically

significant Assiut Journal For Sport Science Arts 
differences at significance $(\cdot .0)$ for the body components variables in favor of the post measurements for the experimental group where the difference between the means of pre and post measurements for $\mathrm{BH}$ is (17.23) Kgm with improvement percentage of $15.12 \%$ for the post measurement, the difference between the means of pre and post measurements for BMI is(9.12)with improvement percentage of $(21.83 \%)$, the difference between the means of pre and post measurements for BF is (11.64)with improvement percentage $(34.99 \%)$ the difference between the means of pre and post measurements for $\mathrm{FW}$ is (15.75)with improvement percentage of (39.91\%)the difference between the means of pre and post measurements for LBM is 2.36 with improvement percentage of $(2.87 \%)$.

The researcher recommends that this decrease in body fats was because applying aerobics exercises which agrees with Fathy Nada's study (2007) when he noticed a reduction of body fats and an increase in motor performance due to applying legalized motor programs on morbid obesity people, the researcher also sees that using aerobics exercises applied scientifically besides the dietary instructions for morbid obesity students led to high improvement rates in FW and BF.

Ibraheem Saleh (2009) says that aerobics burn fats, participate in weight loss, stimulate body building and help to train better. $(\wedge \varepsilon: 1)$

This agrees with Hussein Al-Dawoody's (2015) study that training programs led to weight loss and had a positive effect on some of physical and physiological variables, so it's important to apply such programs for its positive effects.

Thus, the first assumptions applies which stats "that there are statistically significant differences between pre and post measurements means for the body components variables (BH - BMI - BF - FW LBM) in favor of the post measurements for the experimental group."

Second assumption related results discussion

The second assumption stats that there are statistically significant differences 
between pre and post measurements means for the body components variables (BH - BMI - BF - FW LBM) in favor of the post measurements for the control group?

Through displaying table (5) results and chart (2) it's clear that there are no statistically significant differences at significance ( .$\bullet$ )for the body components variables in favor of the post measurements for the control group where the difference between the means of pre and post measurements for $\mathrm{BH}$ is $2.5 \mathrm{Kgm}$ with improvement percentage of $(2.15 \%)$ for the post measurement, the difference between the means of pre and post measurements for BMI is(0.82)with improvement percentage of (1.93\%), the difference between the means of pre and post measurements for $\mathrm{BF}$ is (0.62)with improvement percentage $(1.99 \%$, the difference between the means of pre and post measurements for FW is (1.7)with improvement percentage of (4.44\%)the difference between the means of pre and post measurements for LBM is
(1.44) with improvement percentage of (1.72\%).

The researcher says that those results were because of not using the training program using aerobics exercises applied on the experimental group.

Fonseca et al's. (2013) (13) study that using aerobics programs along with power exercises are the main pillars of morbid obesity sports treatment. so, the study recommends using individual training programs for them.

This led to absence of improvement for the control group as they didn't participate in any training programs weather they were part of the studied program or not. So, there are no statistically significant differences means of pre and post measurements in body components variables for the group under research.

\section{Third assumption related results discussion}

The third assumption stats that there are statistically significant differences between post measurements means of experimental and control groups for the body components variables (BH $\mathrm{BMI}-\mathrm{BF}-\mathrm{FW}-\mathrm{LBM}$ ) in favor of the post measurements 
for the experimental research sample?

Through displaying the results of table 6 and chart 3 we can notice that there are statistically significant differences at significance $(\because \cdot 0)$ for the body components variables in favor of the post measurements for the control group where the difference between the means of pre and post measurements for $\mathrm{BH}$ is $16.9 \mathrm{Kgm}$ with improvement percentage of $(14.89 \%)$ for the post measurement, the difference between the means of pre and post measurements for BMI is(8.83)with improvement percentage of $(21.28 \%)$, the difference between the means of pre and post measurements for BF is (9.22) with improvement percentage $(30.21 \%$, the difference between the means of pre and post measurements for $\mathrm{FW}$ is (12.87)with improvement percentage of $(35.24 \%)$ the difference between the means of pre and post measurements for LBM is (2.51) with improvement percentage of $(3.05 \%)$

The researcher recommends that the statistically significant differences between the means of post measurements for the control and experimental groups because of using the experimental aerobics training program where it contributed effectively in weight loss of the experimental sample.

Those results agrees with Amal Mefreg's study (2006) (4) which stated as a main result that the used program led to weight loss, decrease in fats thickness, absolute and relative fat weight, and body plan for the experimental sample.

This also agrees with Fathy Nada's study (2007) when he noticed a reduction of body fats and an increase in motor performance due to applying legalized motor programs on morbid obesity people, and agrees with Hussein AlDawoody's (2015) (7) study that training programs led to weight loss and had a positive effect on some of physical and physiological variables, so it's important to apply such programs for its positive effects.

The researcher also sees that this obvious improvement in BMI for the experimental group which reached (21.28\%)improvement percentage by $(32.65) \mathrm{kgm} / \mathrm{m} 2$, contributed in its shift from 
being categorized as morbid obesity class 3 with a mean of (41.77) $\mathrm{kgm} / \mathrm{m} 2$ according to world health organization to morbid obesity class 1 with mean of $(32.65) \mathrm{kgm} / \mathrm{m} 2$ which means shifting two classes considered an extinguishment for the program and fulfills the research purpose.

WHO refers (2012) that it depends on BMI in all its researches to identify this international phenomena and to suggest solutions, an individual is considered fat if his degrees fall between $(30,34.99)$ $\mathrm{kgm} / \mathrm{m} 2$ and this is class 1 then $(39.99,35) \mathrm{kgm} / \mathrm{m} 2$ and this is class 2 and finally morbid obesity if the degree was 40 $\mathrm{kgm} / \mathrm{m} 2$ or above $(0 \leqslant: 1)$ ).

Then the third assumption is true which stats that "there are statistically significant differences between post measurements means of experimental and control groups for the body components variables (BH $\mathrm{BMI}-\mathrm{BF}-\mathrm{FW}-\mathrm{LBM})$ in favor of the post measurements for the experimental research sample".

\section{Conclusions:}

- there are statistically significant differences at 0.05 level between post measurements means of experimental and control groups for the body components variables $(\mathrm{BH}-$ $\mathrm{BMI}-\mathrm{BF}-\mathrm{FW}-\mathrm{LBM}$ ) and in decreasing body fats for morbid obesity people, the percentage varied between $(\%$ \% $r \leqslant: \%$ : . ०) compared to pre measurements for this group.

- The absence of statistically significant differences at 0.05 level for morbid obesity students who didn't participate in the program in body components variables which proves the effectiveness of the program in favor of experimental research sample.

\section{Recommendations:}

- Using aerobics under research for fats decrease and raising fitness level for morbid obesity students with in research sample criteria.

- Raising sports activities teachers and students awareness about the importance of using aerobics to lose weight for morbid obesity students through sports activities held inside the school - Doing similar researches on different age levels with limiting training loads to suite every level besides doing more researches and scientific 
studies contributing to body fats decrease for all the students in different stages.

\section{References:}

1. Ibraheem Muhammad Saleh (2009): aerobics program effect on decreasing fats percentage at pre competition levels for body building players, unpublished master's thesis, Al-Sadat physical education faculty, Monoufia university

2. Abou El Ela Ahmad Abdulfattah (1996): training load and athletic health positives and negatives, House of Arabic literature, Cairo

3. Ahmad Nassr El-Deen (2003): sports physiology theories and applications, first edition, House of Arabic literature, Cairo

\section{4-.Amal Muhammad Mefreg} (2007): the effect of a proposed rhythmic aerobic arts program and used themes on weight loss, fats thickness and stress for ladies (30 to 45 years), the scientific magazine issue 52 , physical education faculty, Helwan university.

5. Bastaweesy Ahmad Bastaweesy (2014): fundamentals of developing muscular power in the field of events and sports games, modern book center, Cairo.
6. Jassem Ramadan Ali (2010): Kuwait experiment in putting the national plan of physical activity, the third arab conference for obesity and physical activity, Manama, Bahrain

\section{Hussein Ali Al-Dawoody} (2015): the effect of aerobics diet program on physical and physiological variables for morbid obesity women using computer, published scientific research, the international scientific conference for heath and sports sciences, Assiut university, Egypt.

\section{Aly Fahmy Albeek(1993) :} sports training planning, house of knowledge , Alexandria,.

\section{Fathy Muhammad Nada} (2006): physical activity related changes in body fats and motor performance for morbid obesity children, faculty of education magazine issue 5, Kafr el sheikh university.

10. Muhammad Hassan Allawy (1994): science of sports training, 13th edition, house of knowledge, Cairo.

\section{Neamaat Ahmad} Abdulrahman (2000): aero activities, first edition house of knowledge, Cairo

12. American Society of Metabolic (2012) I Bad iatric 
surgery (ASMBS) and obesity society

\section{Fonseca-Junior SJ, Sá} CG, Rodrigues PA, Oliveira AJ, Fernandes-Filho

J.(2013): Physical exercise and morbid obesity: a systematic review. Arq Bras Cir Dig.

14. Kolterman OG, Insel J, Sackow M \& Olefsky M. (2001); Mechanisms of food resistance in human obesity. Journal of Clinical Investigation .

15. Nyad's Diana and Hogens, Lyle (1999): Basic training for woman total fitness program, Just 30 minutes a day. The physical educator vol.35 No.4,. George. D.:
Crash training to state championship, Track Coach, Formerly Track Technique, No. 147, Spring

16. Roudsepp, S.D , Chan B.H. \& libhke., perri, M.G., Riley, J.R.;(2002) Discrepancy between actual and ideal body images, Impact on eating and exercise behaviors. Eating Behavior, 1 (2), 153-60

17. WHO expert consultation (2004): Appropriate bodymass index for Asian populations and its implications for policy and intervention strategies. The Lancet 